\title{
Unsteady Aspects of Lean Premixed-Prevaporized (LPP) Gas Turbine Combustors: Flame-Flame Interactions
}

\author{
Sulabh K. Dhanuka ${ }^{1}$, Jacob E. Temme ${ }^{2}$ and James F. Driscoll ${ }^{3}$ \\ Michael J. Foust ${ }^{4}$, Kent H. Lyle ${ }^{5}$ \\ 1,2,3 Department of Aerospace Engineering, \\ University of Michigan, Ann Arbor MI 48109 \\ ${ }^{4,5,6}$ General Electric Aviation, Cincinnati OH 45215
}

\begin{abstract}
This work quantifies several sources of unsteadiness that exist within a Lean PremixedPrevaporized (LPP) gas turbine combustor that was operated at elevated pressures using Jet-A fuel. Flame-flame interactions and shear layer vortex shedding, which can be sources of combustion instabilities, are quantified with PIV and PLIF diagnostics. Flame-flame interactions occur because LPP aircraft combustors employ a premixed Main flame that is anchored by the non-premixed Pilot flame. The measured degree of unsteadiness is the standard deviation of: a) flame surface density, b) flame length, c) vorticity in shear layer, and d) recirculation zone size. The flame surface density profile was broad, indicating that large flame motions occur. Flame length increases non-linearly with fuel flowrate. Intense vortices in the shear layer are more than twice the average vorticity, indicating the need for unsteady modeling. Chamber pressure and liquid fuel flow rates were varied. Velocity fields for the five reacting cases were similar but they differed from the two non-reacting cases. Heat release causes the recirculation zone shape to change from ellipsoidal (for the reacting cases) to toroidal (for the non-reacting cases). Methods were developed to image Jet-A spray flames at $3 \mathrm{~atm}$. using formaldehyde fluorescence.
\end{abstract}

\section{Introduction}

There have been relatively few previous studies of lean premixed, prevaporized (LPP) combustors that have provided images of the locations of flames, shear layers and recirculation zones [1-4].

\footnotetext{
${ }^{1}$ Research assistant, Member, AIAA EXXON R\&D, Houston TX

${ }^{2}$ Research assistant, Member AIAA

${ }^{3}$ Professor, AIAA Fellow

${ }^{4}$ Manager, Combustion Aero Technology and Design, Member AIAA

${ }^{5}$ Engineer, Combustion Aero Technology and Design, Member AIAA
}

Such measurements are needed to explain why LPP can to lead to significant reductions in NOx emissions [5-8] and to find ways to reduce the combustion instabilities that also can occur [5]. LPP devices operate on liquid fuel, which is a requirement for aircraft applications. In contrast, there have been many studies of LP (lean premixed) devices [9-16], which operate on gaseous fuels for ground-based gas turbine power plants. One complication associated with LPP devices is that they contain two flames which interact. For aircraft 
operation most of the fuel is burned in a premixed flame (called the Main flame) that is anchored by a smaller non-premixed Pilot flame. For certain offdesign conditions the flame-flame interaction causes unsteady anchoring of the premixed Main flame, which is a possible source of combustion instabilities [17, 18]. A serious obstacle to LPP research is that sprays and heavy hydrocarbons create intense flame luminosity at elevated pressures that interferes with PLIF (Planar Laser Induced Fluorescence) and PIV (Particle Image Velocimetry) diagnostics. Methods to overcome these obstacles are described below. The focus of the present work is to identify and measure several new parameters that quantify the level of unsteadiness associated with LPP, so that these parameters can be used to assess Large Eddy Simulations (LES).

A combustor flame tube was selected that has a simple cylindrical geometry, but care was taken to mount a realistic LPP fuel injector at the upstream end in order to include the real sources of unsteadiness that often have been omitted in previous work. The LPP fuel injector that was selected is called TAPS (Twin Annular Premixing Swirler) [6]. It is a preliminary design version that is similar to, but not identical to an actual production device. It provides realistic flame-flame and flameshear layer interactions because it creates an outer premixed Main flame that interacts with an inner non-mixed Pilot flame. It also creates a strong shear layer that contains shed vortices that interact with the premixed Main flame. Run conditions were chosen to lie along the lower pressure range of an engine operating line.

Relatively large flow rates (up to $0.38 \mathrm{~kg} / \mathrm{s}$ ) of air were preheated to $505 \mathrm{~K}$ and the pressure was varied up to $4.5 \mathrm{~atm}$. The level of swirl that is introduced by the TAPS swirl vanes is similar to that of an actual engine, in order to accurately reproduce the precession of the recirculation zone. Finally, the TAPS liquid fuel injection and atomization process that was used is representative of an engine. Correctly reproducing the Jet-A fuel spray of under engine operating conditions is important to understand the unsteadiness associated with the time lag associated with droplet atomization, which is another potential source of combustion instability $[17,18]$.
To quantify the degree of unsteadiness, the following parameters were selected for measurement. Note that these parameters can be computed with LES but not with RANS (Reynolds Averaged Navier Stokes) computations.

a) standard deviation of flame surface density

(i.e., flame brush thickness),

b) standard deviation of fluctuations of the length of Main and Pilot flames,

c) standard deviation of fluctuations of vorticity and location of the shear layer, and

d) standard deviation of fluctuations in recirculation zone location and size.

If these parameters are large, it indicates that the premixed and unsteady nature of LPP causes large deviations in the positions of the Main flame, the Pilot flame, the shear layer and the primary recirculation zone which would require unsteady (LES) modeling. The level of unsteadiness was systematically varied by altering the ratio of the fuel flow rate of the pilot flame to that of the main flame. When this ratio is decreased far below the design value it was observed that the base of the main flame was poorly anchored so it began to oscillate, which was recorded using a high speed digital camera and is reported in a previous paper [1]. A strong coupling was observed between oscillations of the flame base (in the stream wise direction) and the acoustic pressure. The present work focuses on the sources of the unsteadiness associated with the flame-flame interaction and the shed vortices.

\section{Concept of Lean Premixed-Prevaporized Combustion}

A schematic of LPP combustion is seen in Fig. 1; a premixed, prevaporized Main flame surrounds a central non-premixed Pilot flame. The liquid Main fuel (Jet-A) is injected as a jet-in-across-flow [6]. Because of the high velocities associated with the Main air, most of the Main flame is lifted downstream, which provides time for the Main fuel to vaporize and mix with the Main air prior to combustion. To vaporize the fuel it was necessary to preheat the air to $505 \mathrm{~K}$ and to run at realistic air mass flow rates and equivalence ratios associated with the lower pressure region of the engine operating line. This provides the correct momentum ratio of the Main fuel jet to the Main air stream, to achieve realistic spray properties and vaporization. 
Since the Pilot is not lifted, little air can premix into it, so it is a non-premixed flame that surrounds a fuel-rich region. A stoichiometric contour is expected to occur at the Pilot fuel-air boundary, which is best for flame stability but not desirable from a NOx standpoint. Our results will show that the Pilot flame overlaps the inner edge of the Main flame. Since the Pilot is needed or else the Main flame will blow out, it follows that this flame-flame interaction is important.

The flow pattern in Fig. 1a may seem to be complicated, however the physics of most interest can be simplified to that of the shear layer shown in Fig. 1b. This shear layer lies between the highspeed Main fuel and air mixture on the top side, and hot products and radicals from the Pilot that enter on

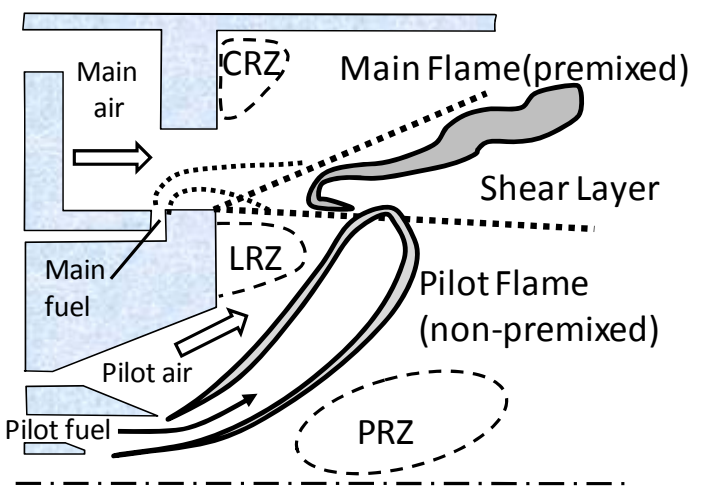

(a)
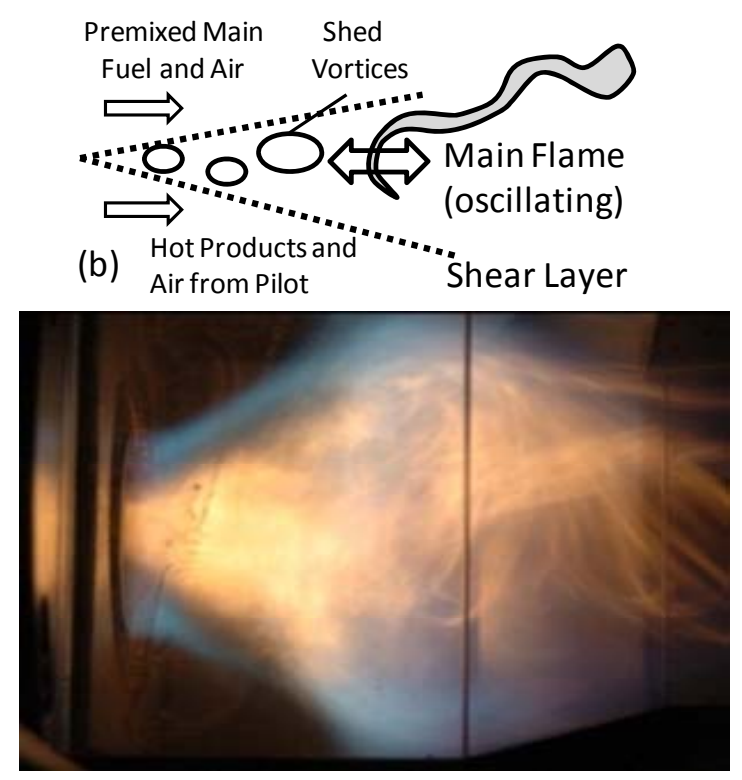

the bottom side. The location of the Main flame with respect to this shear layer is of fundamental importance. Vortices are shed in the shear layer and it is useful to know if these vortices impinge on the Main flame and if they cause unsteadiness. The degree of unsteady oscillations of the Main flame properties also are of interest. It is noted that the realistic LPP device shown in Fig. 1 is designed to provide nearly "ideal" conditions in the shear layer (where there is lean, premixed pre-vaporized combustion), yet the rest of the flow field, including the Pilot flame, is "non-ideal" from a NOx standpoint, but is necessary to insure that the Main flame does not flash back, blow out, or move too close to the walls. Figure 2 is a photograph of the reaction zone generated by the LPP injector in our facility, which is described in the next section.

Fig.1. General Features of Lean Premixed Prevaporized (LPP) Combustion Deduced From the Measurements Below. (a) flow and flame patterns, which appear to be complicated, but the relevant physics reduce to that of (b) the shear layer that contains the premixed Main flame, in which most of the fuel burns.

Figure 2. Photograph the Jet-A flame in the Michigan combustor, which is described in the next section. 


\begin{tabular}{|c|c|c|c|c|}
\hline Author & Ref. & velocity & flame & comments \\
\hline & & data? & data? & \\
\hline \multicolumn{5}{|c|}{ LPP (i.e., liquid fuel) flow field measurements } \\
\hline Present work & & yes & yes & PLIF, PIV, 4.5 atm, Jet-A \\
\hline Dhanuka, Driscoll & 1,2 & yes & no & PLIF, PIV, 4.5 atm, Jet-A \\
\hline Seyfried, Linne, et al. & 3 & no & yes & PLIF, 3.2 atm, kerosene, pilot only \\
\hline Meier et al & 4 & no & yes & PLIF, 6 atm, kerosene \\
\hline \multicolumn{5}{|c|}{ LPP liquid fuel computations } \\
\hline \multicolumn{5}{|l|}{ none } \\
\hline \multicolumn{5}{|c|}{ LP (i.e., gaseous fuel) flow field measurements } \\
\hline Stopper and Meier & 9 & yes & yes & PLIF, PIV $6.0 \mathrm{~atm}$, preheated \\
\hline Cheng, Johnson et al & 10 to 12 & yes & no & PIV, 8 atm, preheated \\
\hline Nogenmyr, Fuerby et al & 13 & yes & yes & PLIF, PIV, 1 atm, no preheat, unconfined \\
\hline Roux, Poinsot et al. & 14 & & & LDV, 1atm, no preheat, confined \\
\hline $\mathrm{Ji}$, Gore & 15 & yes & no & PIV, 1 atm, no preheat \\
\hline Lee, Santoro, et al. & 16 & no & yes & PLIF, 2.6 atm, preheat \\
\hline \multicolumn{5}{|c|}{$\underline{\text { LP (i.e., gaseous fuel) computations }}$} \\
\hline Eggenspieler, Menon & 19 & yes & yes & LES G-Eqn + flamelet chemistry \\
\hline Kim, Menon, Mongia & 20 & yes & yes & LES G-Eqn + flamelet chemistry \\
\hline Huang, Yang et al. & 21 to 24 & yes & yes & LES G-Eqn + flamelet chemistry \\
\hline Roux, Poinsot et al. & 14 & yes & yes & LES + Flame surface density eqn. \\
\hline Selle, Poinsot et al & 25 & yes & yes & LES + Flame surface density eqn. \\
\hline Fureby et al. & 13,26 & yes & yes & LES G Eqn \\
\hline \multicolumn{5}{|c|}{ Related non-premixed gas turbine flow fields (not LPP) } \\
\hline Menon and Patel & 27,28 & yes & yes & LES of non-premixed spray \\
\hline Weigand, Meier, et al. & 29 to 31 & yes & yes & PLIF, PIV, 1 atm, nonpremixed \\
\hline Janus, Janicka & 32 & yes & yes & PLIF, LDV, 2 atm, nonpremixed \\
\hline
\end{tabular}

Table 1. Previous LPP (liquid fuel) and LP (gaseous fuel) gas turbine combustor studies and some related non-premixed cases for which velocity and/or flame properties are reported. 
Previous work is listed in Table 1, which is separated into LPP (i.e. liquid fuel) and LP (i.e., gaseous fuel) studies. Only studies that report velocity fields or flame properties are listed. The present work is one of the first to apply both PIV and PLIF to an LPP combustor. Seyfreid et al. [3] recorded the PLIF signal from kerosene vapor in an LPP device to identify where the liquid fuel was vaporizing. Meier et al.[4] imaged $\mathrm{OH}$ to mark the flame locations in a kerosene-fueled staged combustor that had Main and Pilot flames and is similar to an LPP device. Previous LP (gaseous fueled) experiments that have provided velocity and/or flame data were operated by the research groups of Meier, Cheng, Fureby, Poinsot, Gore, Janicka, and Santoro [9-16]. In these studies no Pilot flames (or flame-flame interactions) were considered since LP devices are designed for ground-based power generation and a Pilot flame is not needed. Table 1 also lists some papers describing nonpremixed combustors [29-32] to provide comparisons to LPP results.

LES computations of spray combustion were published by Menon and Patel [27, 28]. They simulated the n-heptane spray-turbulence interactions with a Lagrangian stochastic separated flow model, but their non-premixed conditions were not LPP. LES was used to determine the residence times of fluid elements and drops, which follow complicated spiraling flow paths when they are entrained into recirculation zones. Their LES also shows that flames can jump between several different recirculation zones, each of which offers a new flame anchoring site. These unsteady aspects cannot be simulated with RANS. Also listed in Table 1 are the LES studies of LP (gaseous fueled) devices conducted by the groups of Yang, Menon, Poinsot and Fuerby [19-26].

\section{Experimental Apparatus}

The experiments were conducted in the University of Michigan High-Pressure Gas Turbine Combustor Facility. The outer cylindrical pressure vessel is $117 \mathrm{~cm}$ long and has an inside diameter of $21 \mathrm{~cm}$, as seen in Fig. 3. The first $66 \mathrm{~cm}$ of the vessel is the flow straightener that contains honeycomb and ceramic beads that were optimized to reduce the flow spatial non-uniformities to less than $8 \%$. The second $51 \mathrm{~cm}$ long section encloses the inner cylindrical combustor, which is $14.6 \mathrm{~cm}$ in diameter. The cylindrical wall contains 4000 dilution air holes; each has a diameter of $0.88 \mathrm{~mm}$. The LPP fuel injector is mounted on the upstream end of this cylindrical combustor. Liquid Jet-A was forced into the fuel injector using a nitrogen gas pressurization system. The combustion air is pressurized by external compressors and is heated to $505 \mathrm{~K}$ by a $250 \mathrm{~kW}$ electrical heater. Air flow rate is metered by a choked flow orifice, while a downstream valve controls the operating pressure. Optical access is provided on three sides by 5 inch diameter fused silica windows on the outer pressure vessel and rectangular fused silica windows on the inner cylindrical combustor.

PLIF and PIV were used to image both the time-averaged and the instantaneous patterns in the flame, shear layer, and vorticity structure. The diagnostics are described in Appendix A. It was found that formaldehyde PLIF successfully provided images of the flame location for pressures up to 3.0 atm under these challenging high pressure, liquid fuel conditions. Higher pressure application of PLIF is believed to be possible, but requires further study. The main challenge is properly gating the PLIF and PIV cameras to filter out the intense luminosity associated with spray combustion at elevated pressures. The flame is identified as the location where the gradient of the formaldehyde PLIF signal is a maximum. That is, the formaldehyde PLIF signal itself is a maximum where the fuel concentration is too large to support combustion, but the maximum gradient of the PLIF signal occurs near the fuel-air boundary and marks the flame location, as was shown in a separate calibration study in our laboratory [34]. Prior to this study, accurate images of the flame properties have not been available for a high-pressure Jet-A fuelled LPP gas turbine combustor. 

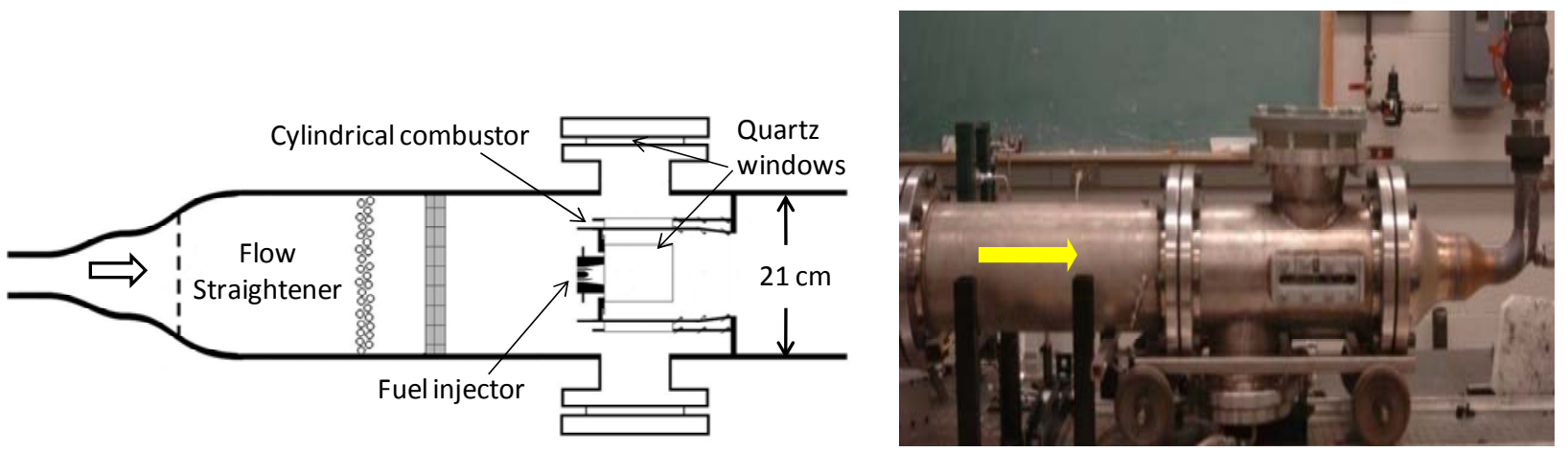

Figure 3. Michigan High-Pressure Gas Turbine Combustor Facility.

\begin{tabular}{|c|c|c|c|c|c|c|c|c|c|c|}
\hline \multirow[t]{2}{*}{ Case } & Flames & \multicolumn{2}{|c|}{ Air Inlet Combustor } & \multirow{2}{*}{ Diagnostics } & \multirow{2}{*}{$\begin{array}{c}\text { Inlet plane } \\
\text { air flow }\end{array}$} & \multirow{2}{*}{$\begin{array}{l}\text { Sidewall } \\
\text { air flow }\end{array}$} & \multirow{2}{*}{$\begin{array}{l}\text { Main } \\
\text { fuel }\end{array}$} & \multirow{2}{*}{$\begin{array}{l}\text { Pilot } \\
\text { fuel }\end{array}$} & \multirow{2}{*}{$\begin{array}{c}\text { Inlet plane } \\
\text { equival- }\end{array}$} & \multirow{2}{*}{$\begin{array}{l}\text { Overall } \\
\text { equival- }\end{array}$} \\
\hline & & temper- & pressure & & & & & & & \\
\hline \multicolumn{2}{|c|}{ Baseline cases } & ature $(\mathrm{K})$ & $(\mathrm{atm})$ & & $(\mathrm{kg} / \mathrm{s})$ & $(\mathrm{kg} / \mathrm{s})$ & flow $(\mathrm{g} / \mathrm{s})$ & flow $\mathrm{g} / \mathrm{s}$ & ence ratio & ence ratio \\
\hline 1 & Pilot and Main & 505 & 2.0 & PIV and PLIF & 0.114 & 0.114 & 2.40 & 0.99 & 0.44 & 0.22 \\
\hline 2 & Pilot only & 505 & 2.0 & PIV and PLIF & 0.114 & 0.114 & 0 & 0.99 & 0.13 & 0.06 \\
\hline 3 & Non-reacting & 422 & 2.5 & & & & 0 & 0 & & 0.00 \\
\hline \multicolumn{11}{|c|}{ Vary pressure, vary fuel flow rate } \\
\hline 4 & Pilot and Main & 505 & 1.0 & PLIF o & 0.114 & 0.114 & 2.49 & 1.17 & 0.47 & 0.24 \\
\hline 5 & Pilot only & 505 & 1.0 & PLIF only & 0.114 & 0.114 & 0 & $1.2-1.9$ & $0.16-0.25$ & $0.08-0.13$ \\
\hline 6 & Pilot only & 498 & 4.5 & PIV only & 0.188 & 0.188 & 0 & 2.78 & 0.22 & 0.11 \\
\hline 7 & Non-reacting & 503 & 4.5 & PIV only & 0.188 & 0.188 & 0 & 0 & 0.00 & 0.00 \\
\hline
\end{tabular}

Table 2. Operating Conditions of the LPP Combustor. The inlet plane equivalence ratio is defined as: [(Main fuel + pilot fuel $) /($ Inlet plane air flow $)] / 0.068$. Overall equivalence ratio $=[($ Main fuel + pilot fuel $) /($ Inlet plane air flow + sidewall air flow)] / 0.068 .

Operating conditions are listed in Table 2. The baseline condition (Case \#1) was chosen because both the PLIF and PIV diagnostics operated well at $2 \mathrm{~atm}$. At 4.5 atm (Cases \# 6 and \#7) the PIV results were satisfactory but the PLIF signal was of marginal quality due to flame luminosity that leaked through the optical filters and electronic camera gating. If additional diagnostic efforts are made, PLIF at above 4 atm should be achievable. Cases 2 and 3 provide comparisons of the Pilot and Main flame to that of the Pilot only and to the Nonreacting flow. The pressure and fuel flow were varied for Cases \#4 to \#7. Table 2 lists two values of the air flow rate; the "inlet plane air flow" is that which crosses the horizontal inlet plane at the upstream end of the cylindrical combustor; it represents $51 \%$ of the total air flow, based on the PIV data. The "sidewall air flow" is the remaining $49 \%$ of the air which enters through dilution holes in the combustor side wall. The "inlet plane equivalence ratio" in Table 1 is the sum of the Main and Pilot fuel flow rates, divided by the inlet plane air flow, divided by the stoichiometric fuel-air ratio which is 0.068 for Jet-A fuel. The overall equivalence ratio includes the dilution air.

\section{Results (a) Locations of Main Flame, Pilot Flame, Shear Layer, Recirculation Zones}

In order to quantify the simple concept of LPP combustion that was shown in Fig. 1a, the timeaveraged locations of the Main and Pilot flames were measured and are shown in Fig. $4 \mathrm{a}$ and $4 \mathrm{c}$ for 
Cases \#1 and \#4, respectively. The two operating conditions are nearly identical, but Case \#1 was run at $2.0 \mathrm{~atm}$. while Case 4 was run at $1.0 \mathrm{~atm}$. First, 200 raw PLIF images were averaged to yield Figs. $4 \mathrm{~b}$ and $4 \mathrm{c}$. It is seen that the maximum formaldehyde signal occurs at the center of the Pilot spray, where conditions are so fuel-rich that combustion is not possible. The flame is located where there is a maximum gradient of the PLIF signal, as was shown in our calibration study [34], and this maximum gradient occurs near the fuel-air boundary. The Pilot flame location first was imaged by running the Pilot only. This resulted in the yellow region shown in Figs. 4a. Then the Main fuel was added; the Pilot flame location (shown in yellow) did not change, but an additional Main flame (shown in grey) was observed.

It is seen in Fig. $4 \mathrm{~b}$ that the left side of the Main flame has a rounded shape and it appears that the Main flame begins at $x=5 \mathrm{~mm}$ downstream of the injector plane $(x=0)$. The exact location of the beginning of the Main flame is difficult to determine because the laser light sheet also begins at $\mathrm{x}=5 \mathrm{~mm}$, but the images indicate that the Main flame begins approximately at $\mathrm{x}=5 \mathrm{~mm}$. The downstream end of the Main flame occurs at $20 \mathrm{~mm}$, so the length of Main flame is $15 \mathrm{~mm}$. The base of the Pilot is visually observed to occur at approximately $\mathrm{x}=0$ $\mathrm{mm}$, which is upstream of the PLIF field of view ( $\mathrm{x}$ $=5 \mathrm{~mm}$ ). The Pilot flame extends to $\mathrm{x}=17 \mathrm{~mm}$. The radial outer edge of the Pilot flame is seen to overlap the radial inner edge of the Main flame. For the lower pressure case $(1.0 \mathrm{~atm})$, Fig. $4 \mathrm{c}$ indicates that the lengths of the Main and Pilot flames are similar to that of the higher pressure case. It is noted that in Fig. 4c the Main flame has less overlap with the Pilot, and its boundaries are more easily identified, than in Fig. 4a. The Main flame in Fig. 4b is observed to exist well upstream of the location where the Pilot flame overlaps the Main flame. This indicates that it is not the overlap of Pilot flame on the Main fuel stream that determines the base of the Main flame; instead the Main flame appears to be stabilized by hot products from the Pilot flame that are carried upstream by a recirculation zone to the base of the Main flame.

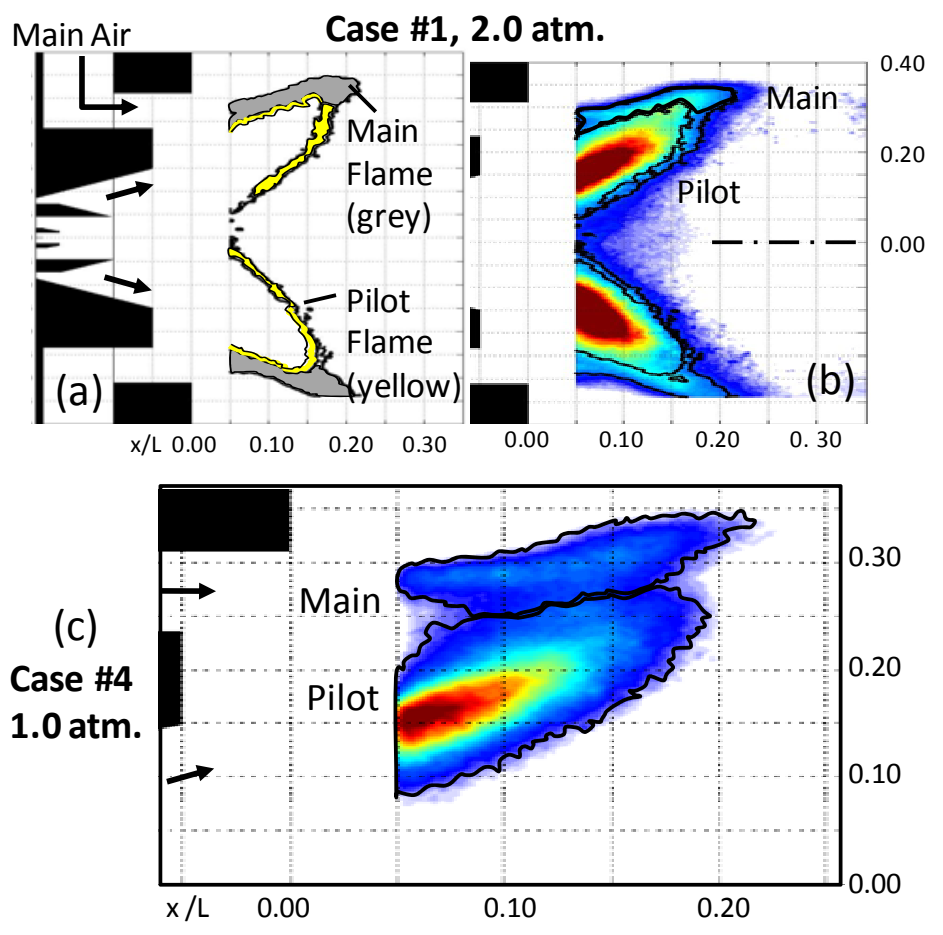

Fig. 4. Mean Flame Locations of Main and Pilot Flames. (a,b): Case \#1: 2 atm, $505 \mathrm{~K}$ air preheat. (c) Case \#4: $1 \mathrm{~atm}$, $505 \mathrm{~K}$ air preheat. Raw formaldehyde PLIF signal seen in (b) and (c); flame boundaries in (a) correspond to maximum gradient in the PLIF signal. 
Time-averaged velocity fields are plotted in Fig. 5 for: Cases \#1 (baseline, Pilot and Main), \#4 (lower pressure, Pilot and Main),\#6 (Pilot only) and \#7 (non-reacting). The dotted white line in Fig. 5a encloses the negative axial velocity region; it is a useful description of the recirculation zone because it is unambiguous. It can be measured exactly with PIV and can be computed with LES. This negative axial velocity region is smaller than the entire recirculation zone, which contains both negative and positive axial velocities. Note that in Figs. 5a and 5b there are positive axial velocities on the centerline, while the non-reacting case (Fig. 5c) displays negative velocities on the centerline. This was consistently observed; all five reacting cases in Table 2 had positive velocities on centerline, while both non-reacting had negative velocities on centerline. This indicates that the heat release greatly distorts the shape of the recirculation zone and the velocity field. Properly modeling this effect of heat release remains a challenge to the modeling community.

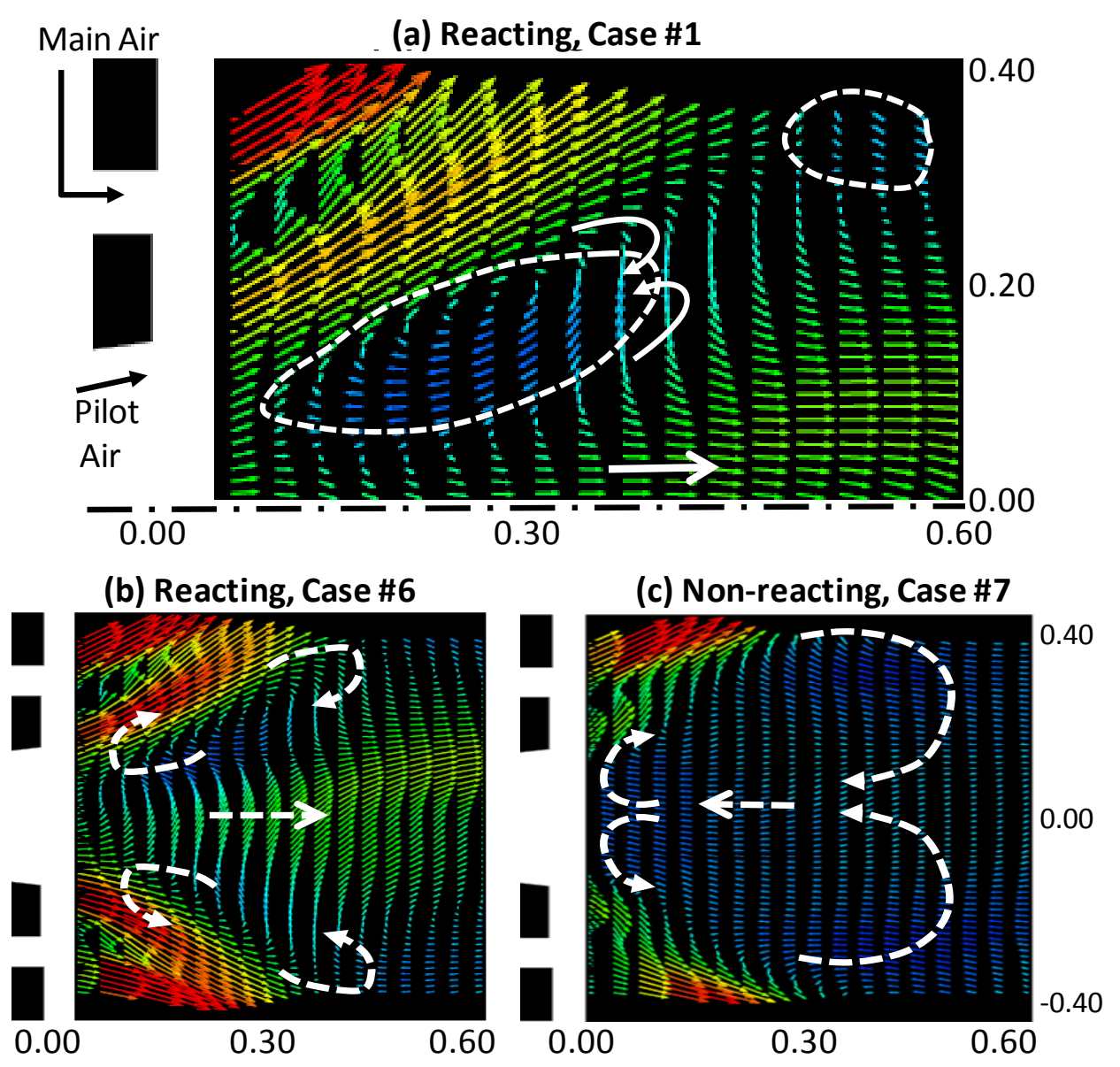

Fig. 5. Mean Velocity Field (a) Reacting, Case \#1, Main and Pilot flames, 2 atm. (b) Reacting, Case \#6, Pilot only, $4.5 \mathrm{~atm}, 498 \mathrm{~K}$ preheat and (c) Non-reacting Case \#7, $4.5 \mathrm{~atm}$. 
(a) Reacting, Case \#6: Axial Velocity (m/s)
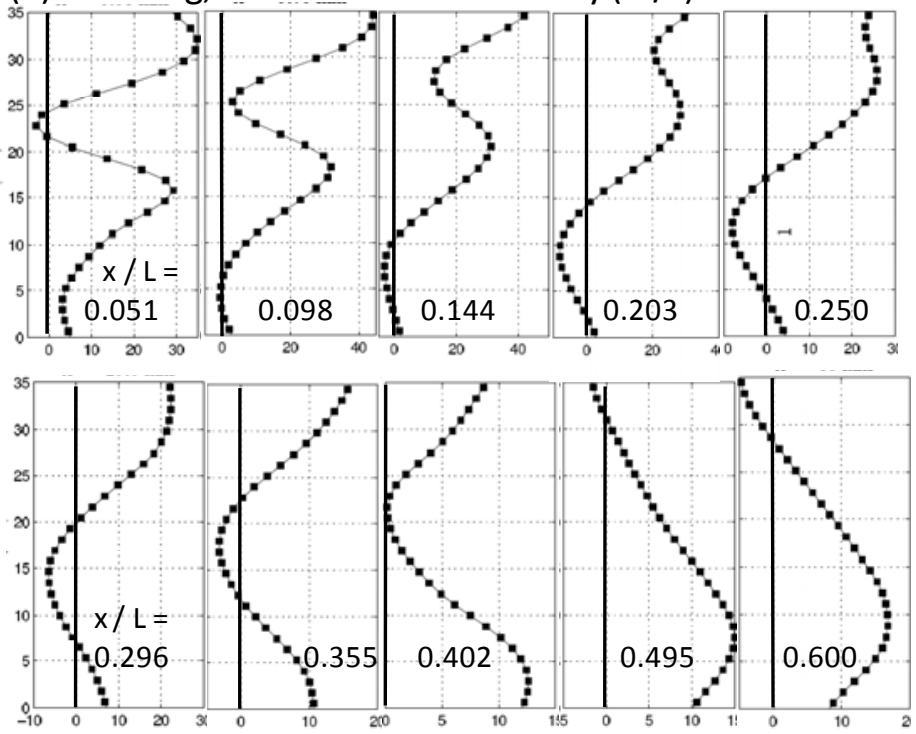

(b) Non-Reacting, Case \#7: Axial Velocity $(\mathrm{m} / \mathrm{s})$

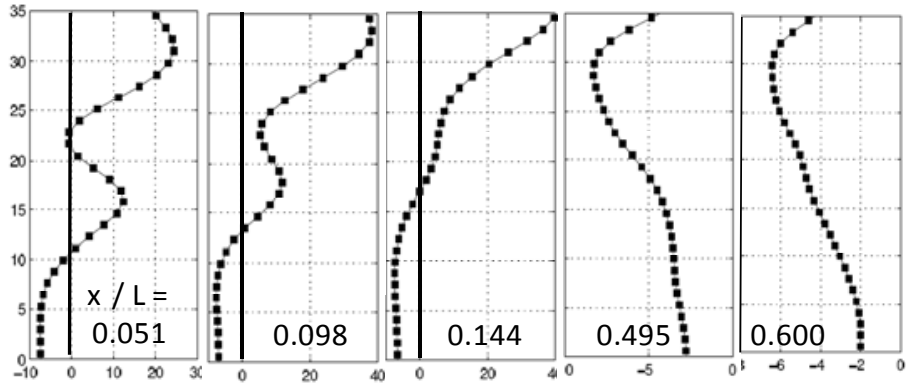

Fig. 6. Profiles of Axial Mean Velocity For (a) Case \#6 (reacting) and (b) Case \#7 (non-reacting).

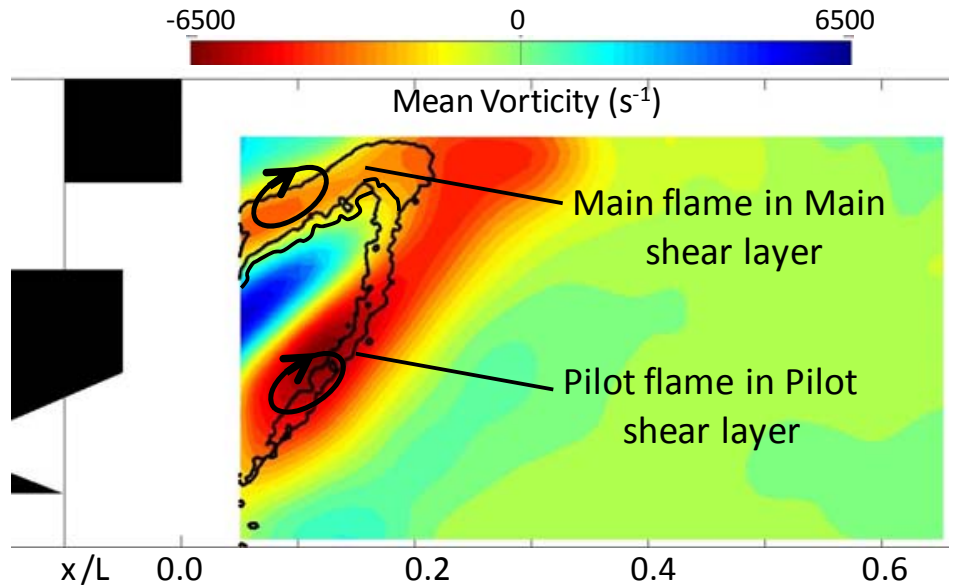

Fig. 7. Main Shear Layer (upper red region) that is identified from the measured contours of mean vorticity. Red indicates large clockwise fluid element rotation. Case \#1 (Main and Pilot flames, $2 \mathrm{~atm}, 506 \mathrm{~K}$ preheat air temperature). Pilot flame also is seen to exist in a shear layer, but it is the Main shear layer that is of importance since most of the fuel burns in the Main flame. 
Figure 7 shows that a strong shear layer exists in this LPP device at the lower (radiallyinward) boundary of the Main air flow. The shear layer is the upper red region where the timeaveraged vorticity component $\left(\omega_{z}\right)$ is large. Contours of the aerodynamics strain rate also were measured and they look similar to Fig. 7. The Main flame is seen to overlap this shear layer. Figure 7 confirms that the simplified view of LPP that appeared in Fig. 1b is correct. The premixed Main flame exists in the shear layer that is fed by premixed reactants on the top side and by hot products from the Pilot on the lower side. The shear layer contains large velocity gradients that exert aerodynamic strain and force the flame base to lift downstream to a location that has a sufficiently small value of strain rate. Premixing is almost certain to occur in this lifted region. Thus the shear layer plays an important role in controlling combustion instabilities and NOx formation in the Main flame, where most of the fuel is consumed.

The typical value of vorticity in the red region of Fig. 7 is $5,000 \mathrm{~s}^{-1}$, which can be explained by the fact that the velocity of the Main air stream is about $40 \mathrm{~m} / \mathrm{s}$ ( as was seen in Fig. 6), and a typical width of the shear layer is $8 \mathrm{~mm}$. The ratio of these two numbers is $5,000 \mathrm{~s}^{-1}$. In Fig. 7 another shear layer (red region) is observed that surrounds the Pilot flame. However this shear layer is less important that the one surrounding the Main flame because the Pilot is non-premixed, stable, and consumes only a small fraction of the fuel.

\section{Results(b) Unsteady Parameters - flame surface density and standard deviation of flame length}

One goal was to quantify whether the locations of the flame and the shear layer experience small deviations from some mean location, or if violent and large deviations are detected, which could be a source of instabilities. The other issue is whether more of the unsteadiness is caused by the premixed Main flame, rather than the Pilot. A premixed flame is free to propagate in space, unlike non-premixed flames. To the naked eye, both the Pilot and Main flames appear to be well-anchored, excessive noise is not detected, and the conditions in Table 2 are far away from those that are found to trigger a combustion instability [1]. However even in this stable mode of operation, large unsteady deviations were measured which indicate that sources of unsteadiness always are present. Fig. 8a is the superposition of fifteen instantaneous flame boundaries for Case \#1. Figures 8b-d contain instantaneous PLIF data; the black lines identify the maximum PLIF signal gradient. The uppermost contours in Fig. 8a are boundaries of the Main flame; they oscillate over a large radial distance to create a broad flame brush. Large oscillations in the length of the Main flame also can be identified.

It was determined that there was a $22 \%$ fluctuation in the length of the Main flame. This value is the r.m.s. deviation of $3.29 \mathrm{~mm}$ divided by the time-averaged value of $15.2 \mathrm{~mm}$, based on contours such as those in Fig. 8. To determine the fluctuations in the Pilot flame length, the same process was repeated with only the Pilot fuel on. Figure 9 shows that the fluctuations in the Pilot flame length are only $5.2 \%, 4.85$, and $6.4 \%$ for the three fuel flow rates considered. Therefore it is concluded that the fluctuations associated with the length of the (premixed) Main flame are three times larger than that of the (nonpremixed) Pilot flame. There are several possible reasons why the Main is a larger contributor to unsteadiness than the Pilot. A premixed flame is more difficult to anchor, the Main flame is subjected to larger gas velocities, and it is farther from the stabilizing hot products in the central recirculation zone. This increased unsteadiness introduced by the premixed combustion represents a new modeling challenge associated with LPP devices. 

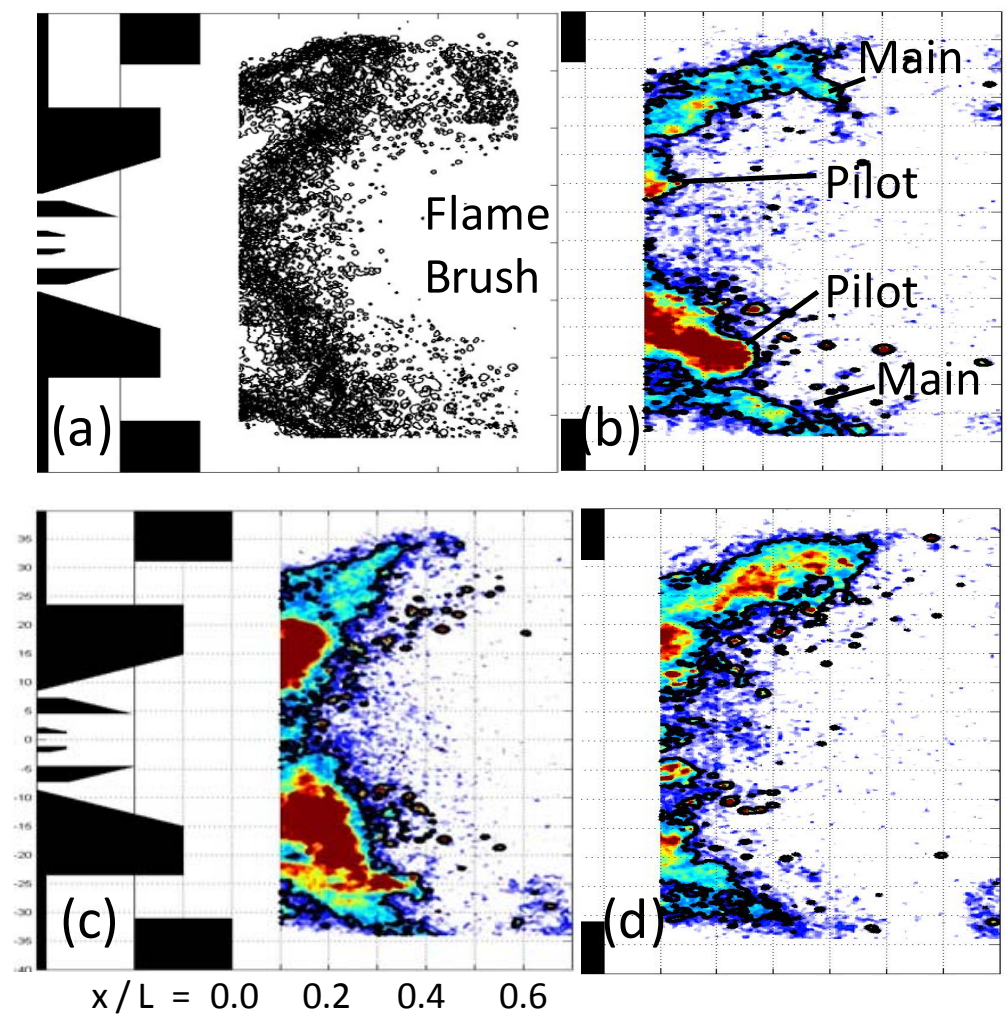

Fig. 8. Unsteady Deviations of the Main and Pilot Flames. Main flame is radially-outermost region. (a) Broad flame brush is observed by plotting 15 instantaneous flame boundaries. (b,c,d) Flames (black lines) extend farther downsteam on one side than on the other at various times, based on instantaneous formaldehyde PLIF images. Case \#1 (Main and Pilot flames, $2 \mathrm{~atm}, 505 \mathrm{~K}$ air preheat temp).

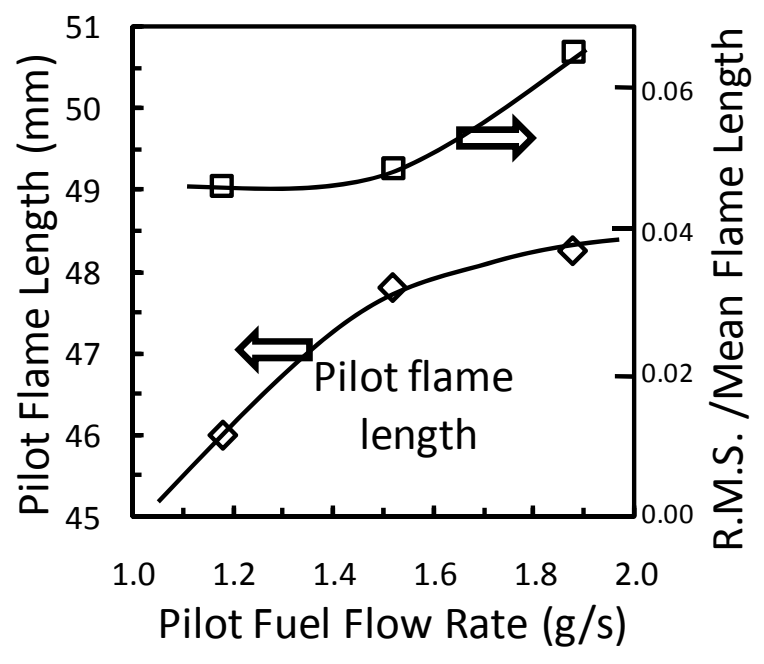

Figure 9. Fluctuations in Length of the Pilot Flame (no Main fueling) indicating the Pilot is Steadier Than Main. (diamond symbols $=$ time-averaged length). Square symbols = standard deviation of flame length. Case \#5. 
The flame surface density $(\Sigma)$ is a parameter that quantifies the unsteady motions of the flame front, and therefore it is useful for the assessment of LES models. Surface density can be computed by two types of LES combustion submodels that incorporate either the G-equation [19-24] or the flame surface density equation [14, 25]. Surface density was measured for Case \#1 and it is plotted in Fig. 10. It is the time-averaged flame perimeter that exists within a small $(2 \mathrm{~mm} x$ $2 \mathrm{~mm}$ ) interrogation box within the measurement plane, divided by the box area. This 2-D value of $\Sigma$ differs from the 3-D value, which is the average flame area per unit volume. However the 2-D value is more useful since it can be determined both from experiment and from LES. $\Sigma$ indicates the probability that an instantaneous flame boundary lies within a given interrogation box. The contours of $\Sigma$ in Fig. 10a are seen to have two branches; the upper branch indicates the probability of finding the Main flame, while the lower branch indicates the probability of finding the Pilot. Surface density is seen to be largest (red) at the radially outward region of each brush region. This indicates that the flame slows down and spends more time at these radially outward locations during its oscillations in the radial direction.
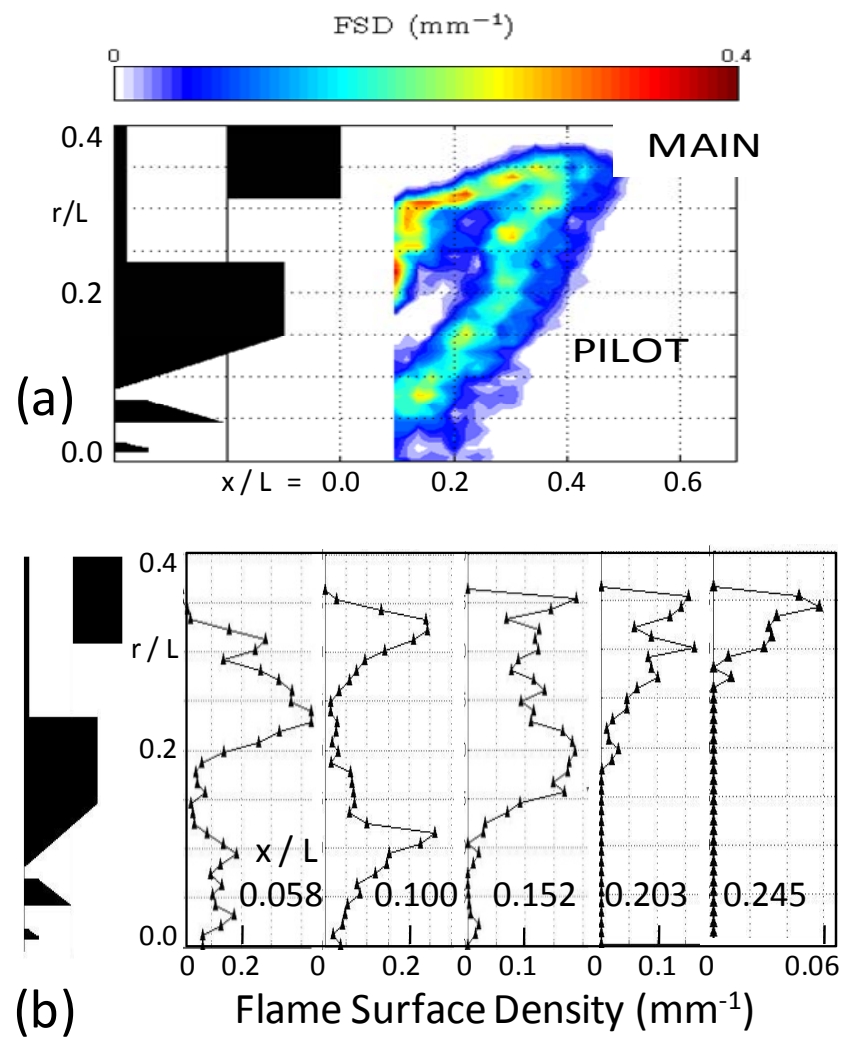

Fig. 10. Flame surface density for Case \#1(Pilot and Main); (a); contours of FSD; (b) Profiles of FSD

The brush thickness also is useful for the assessment of LES predictions, since the brush thickness depends on unsteady motions that LES may be able to resolve but RANS cannot. It is an unambiguous measure of how much the flame deviates in the radial direction from its mean position. Brush thickness is defined as the full width (at half maximum) of the surface density profiles. The profiles appear in Fig. 10b, and the measured brush thickness of the Main and the Pilot are plotted in Fig. 11 for Case \#1. The Main flame extends from $\mathrm{x}=5 \mathrm{~mm}$ to $\mathrm{x}=20 \mathrm{~mm}$ on 
average. The flame length of the Pilot also was measured as the Pilot fuel was systematically increased; results are shown in Fig. 9. As expected, the flame length increased as more fuel was injected. The length of the Pilot is seen to not increase linearly with fuel flow rate, perhaps because a long Pilot extends into the Main air stream, which forces more air into the Pilot.

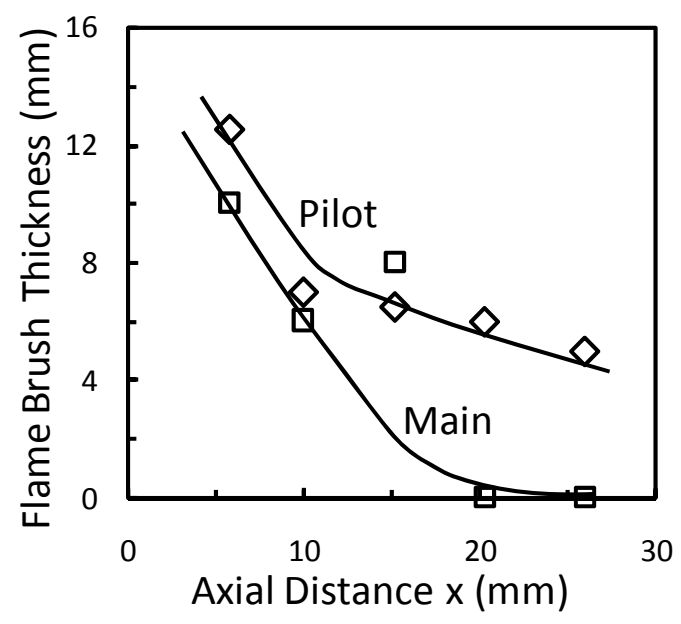

Figure 11. Brush thicknesses of Main and Pilot flames; it is the width of the surface density profiles. Case \#1 (Main and Pilot flames, 2 atm, $506 \mathrm{~K}$ preheat air temperature)

\section{Results (c) Turbulence intensity and Reynolds Stresses}

Turbulence intensity (q) and Reynolds stresses stress parameter $\left(\overline{u^{\prime} v^{\prime}}\right)$ are plotted in Fig. 12 for Cases \#1, \#6 and \#7; q is defined as $\sqrt{\frac{1}{2}\left(\overline{u^{\prime 2}}+\overline{v^{\prime 2}}\right)}$. There are two thin regions in space where both quantities are large. The first region is in the upper left of each image and is inclined with respect to the horizontal. This region is the shear layer associated with the Main air stream. The other region where turbulence intensity is large is near the centerline. This finding is unexpected and is explained in the next section.

\section{Results (d): Comparison of the Non-reacting LPP Flow Field to the Reacting Case}

The recirculation zone is greatly altered by the presence of the flame, as was seen in Figs. 5b and $5 \mathrm{c}$. With no reaction the central recirculation zone is ellipsoidal in shape and the flow moves in the negative $\mathrm{x}$-direction along the centerline in Fig. 5c. With reaction, the time-averaged recirculation zone is toroidal in shape and the flow moves in the positive $\mathrm{x}$-direction along the centerline in Fig. 5b. The size of the primary recirculation zone is considerably reduced in the reacting case. The flow issuing from the pilot annulus appears to issue at a higher velocity than in the non-reacting case while the main flow is largely unaffected.

The explanation for the flow field changes due to heat release is believed to be the following. The positive axial velocity on centerline is due to the geometry of the LPP fuel injector, because previous studies that have employed a central bluff-body do not observe positive axial velocities on centerline. With the present injector the sum of the air through the Pilot and the Main is a fixed number, but the blockage of the flame causes the amount of air flowing through the Main to decrease, which increases the air flow through the Pilot. Measurements confirm that the air through the Pilot was larger in the reacting case. That is, note that in Fig. $5 \mathrm{~b}$ all the axial velocity vectors at the upstream boundary of the field of view $(x=5$ $\mathrm{mm}$ ) are positive, whereas many of the vectors in Fig. 5c (non-reacting) are negative. If the central region of this injector instead was a bluff body, the increased air flow could not enter near the centerline, and it is believed that the axial velocities on centerline would be negative. 

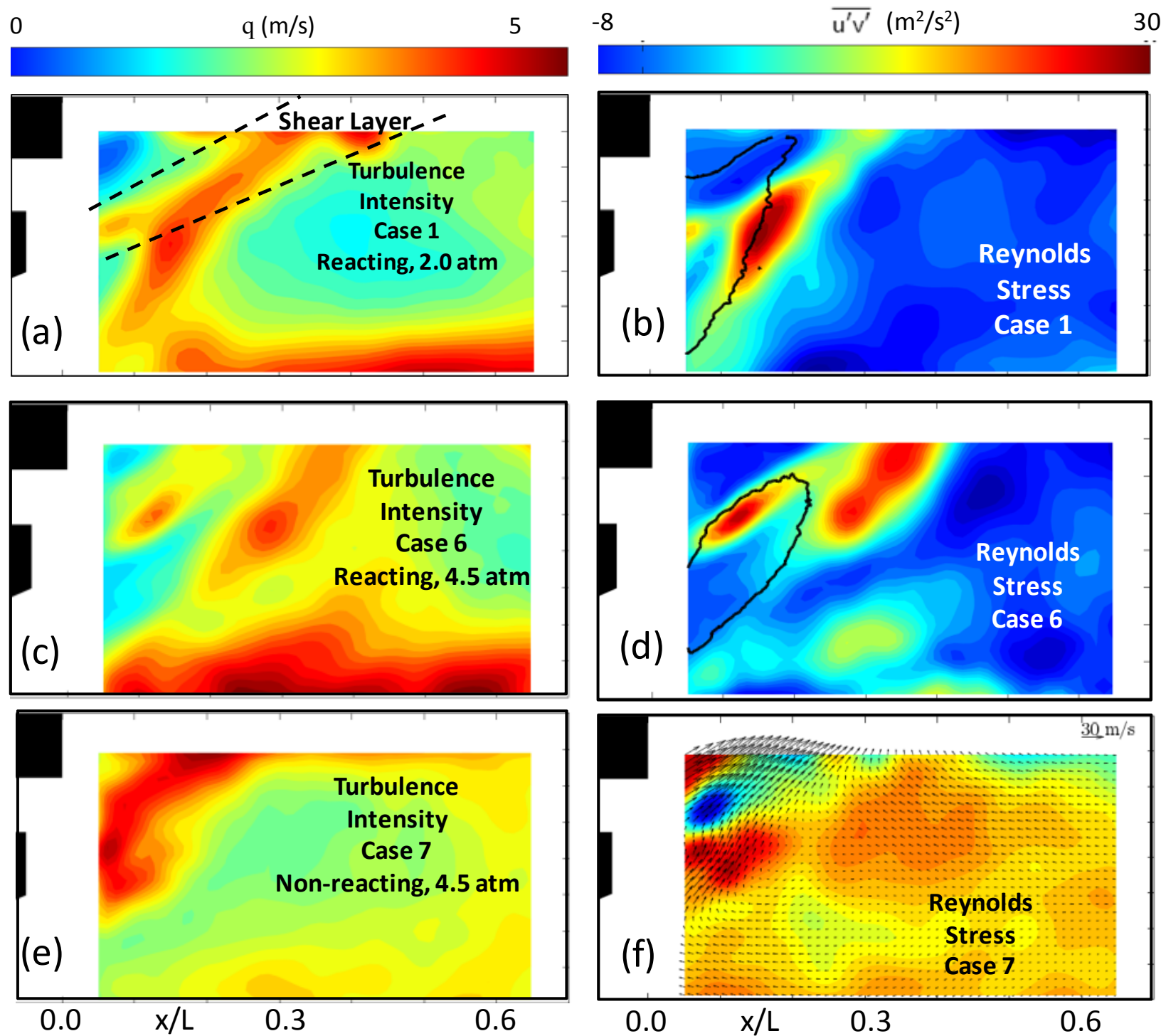

Fig 12. Contours of Turbulence Intensity (q) and Reynolds stress parameter $<u^{\prime}{ }^{\prime}>>$ for Cases \#1 (Main and Pilot)., \#6 (Pilot only), and \#7 (Non-reacting).

Fureby et al. [26] also studied an injector which allowed air to enter near the centerline as well as at an off-centerline annular location. Their triple annular swirler has similarities to the present Pilot air/Main air geometry. They reported that their flame affected their recirculation zone in a manner that is similar to that observed in Fig. 5. They found that the velocity profiles with the flame were markedly different from the non-reacting case; with the flame the axial velocity was positive on the centerline but with no flame the centerline velocity was negative. They noted that LES was not able to predict the positive velocities on centerline close to the injection plane, but was satisfactory at downstream locations. The differences between their LES and measurements were likely due to uncertainties in the upstream boundary conditions, which can differ for reacting and non-reacting cases, and is not due to shortcomings in the LES model. Weber and Dugue [35] also report that heat release causes a reduction of the strength and size of the recirculation zone in a confined geometry. They argue that heat release increases the axial component of momentum, while it does not alter the azimuthal 
(swirl) momentum. Thus it has the effect of reducing the swirl number, and this reduces the pressure gradient and the strength of the recirculation zone.

A second conclusion that is deduced from Fig. 12 is that the flame greatly increases the turbulence intensity near the centerline. Note that in Fig. $12 \mathrm{e}$ there is almost no turbulence near the centerline in the non-reacting case. This is because there are only very small negative axial velocities inside the recirculation zone, which overlaps the centerline (Fig. 5c). However Figs. $12 \mathrm{a}$ and $\mathrm{b}$ show that with the flame present, intense turbulence occurs near the centerline. This is explained by looking at the instantaneous velocity pattern shown in Fig. 13. At this instant in time, the recirculation pattern is not symmetric, so the axial velocity on centerline is positive. The recirculation zone has moved downward, and at a later time it may move upward and be located primarily above the centerline. This radial motion of the recirculation zone is observed to cause two things: it forces positive axial velocity region to move to the centerline for a significant fraction of time, and this motion causes the velocity variations (and thus the turbulence level) on centerline to be greatly increased. This pronounced radial movement of the recirculation zone is not observed in the non-reacting case, so it likely is caused by the motions of the flame, which were documented above.

\section{Results (e) Unsteady shear layer properties}

Since combustion instabilities can be triggered by vortices that are shed in a shear layer $[36,37]$, images were obtained of the mean vorticity and the instantaneous vortex structures. Figure 14 illustrates the instantaneous vorticity field. The mean vorticity field was shown previously in Fig. 7. The typical value of the mean vorticity $\left(5,000 \mathrm{~s}^{-1}\right)$ is the the $40 \mathrm{~m} / \mathrm{s}$ Main air stream velocity divided by the $8 \mathrm{~mm}$ thick shear layer. However the instantaneous vorticity values in Fig. 14 exceed 10,000 s $\mathrm{s}^{-1}$, thus are more than twice the mean value. The individual vortices often have a rotational velocity of $40 \mathrm{~m} / \mathrm{s}$ and a diameter of only $4 \mathrm{~mm}$, which leads to a vorticity of $10,000 \mathrm{~s}^{-1}$.

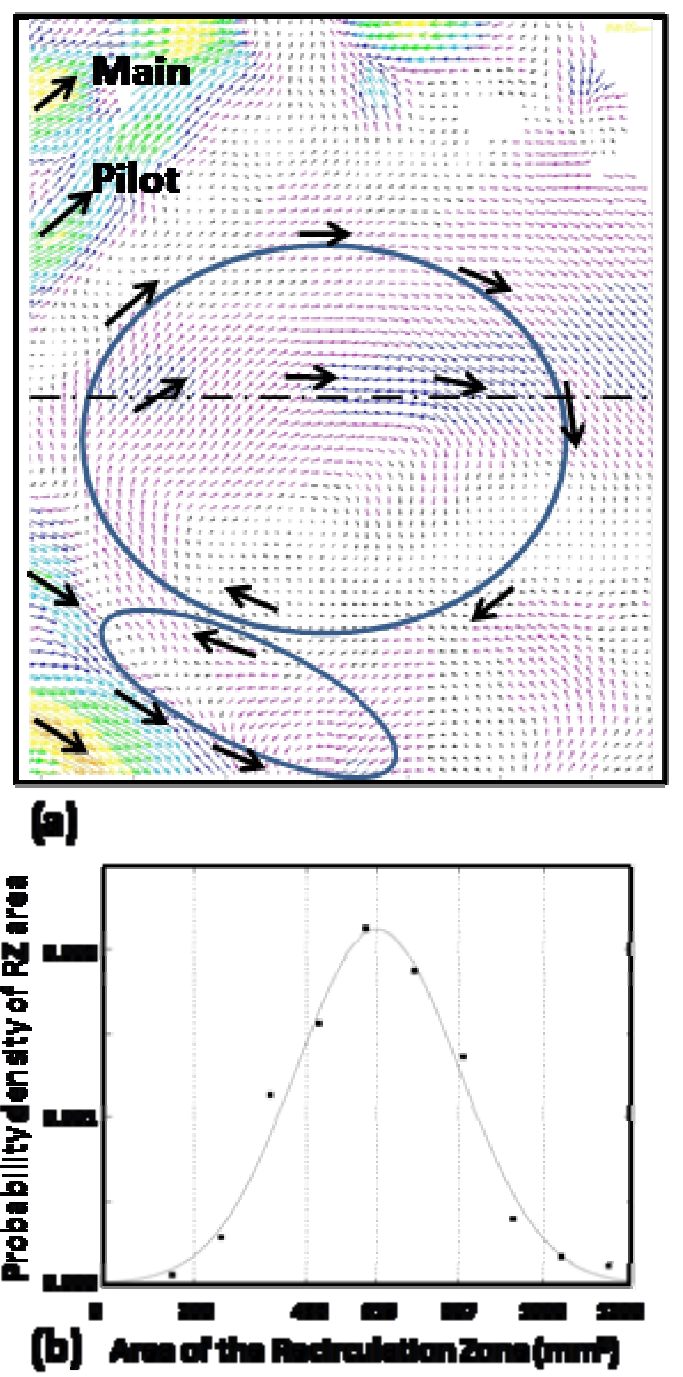

Fig. 13. (a) One instantaneous PIV image showing that the recirculation zone oscillates in the radial direction, which leads to large velocities and large turbulence intensities near the centerline. (b) PDF of the area of the instantaneous recirculation zone. The width of the Gaussian curve indicates the rms variations in recirculation zone area. Case \#1.

The vortices are known to affect the Main flame in several ways; they transport hot products and fresh reactants to help to anchor the reaction zones; they also increase the flame surface area due to their ability to stretch and wrinkle the flame surface. If they are too strong, they can extinguish the reactions. Their vorticity is an indicator of their aerodynamic strain rate. It 
is known that lean premixed flames often extinguish at strain rates of 1,000 to $2,000 \mathrm{~s}^{-1}$. Thus these vortices are sufficiently strong to locally extinguish the Main flame. Such events would cause the reactants to reignite at locations away from the strong vortices, which has the effect of rapidly displacing the reactions in the radial direction. Therefore vortex-flame

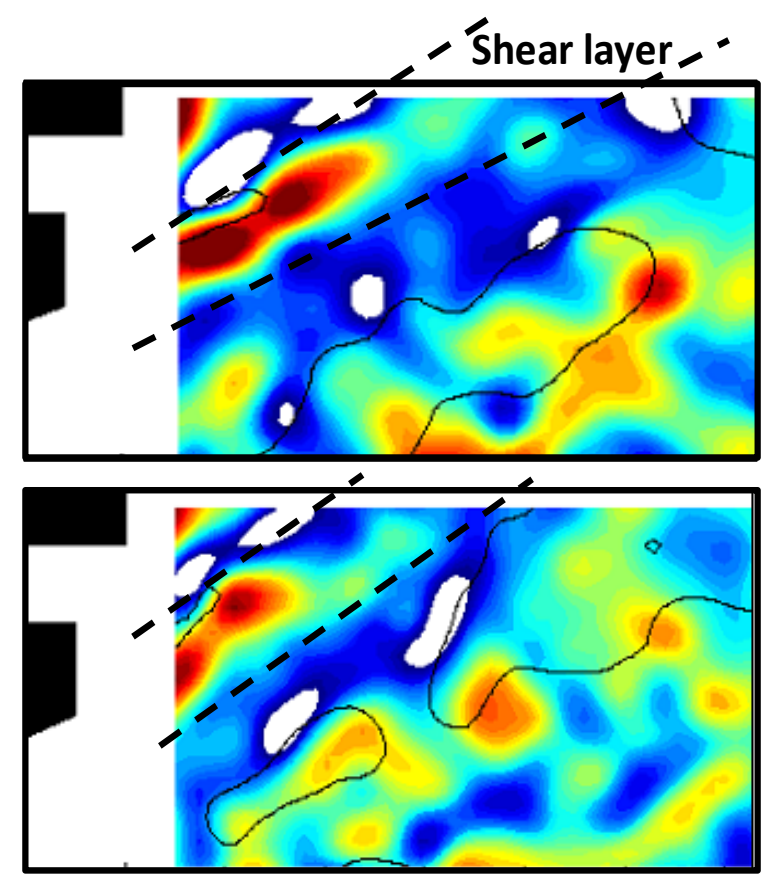

Fig. 14. Shed Vortices in the Shear Layer (red vortices between dotted lines). Red $=$ vorticity of $10,000 \mathrm{~s}^{-1}$ (clockwise rotation). Case \#6; reacting, $4.5 \mathrm{~atm}$. interactions could be responsible for the broad radial movement of the Main flame that was seen in Figs. 4, 8, and 10. A metric that quantifies the variation of vorticity in the shear layer is the PDF of vorticity. This was measured and is plotted in Fig. 15. These values can be predicted by LES, unlike RANS, which only computes the mean vorticity field.

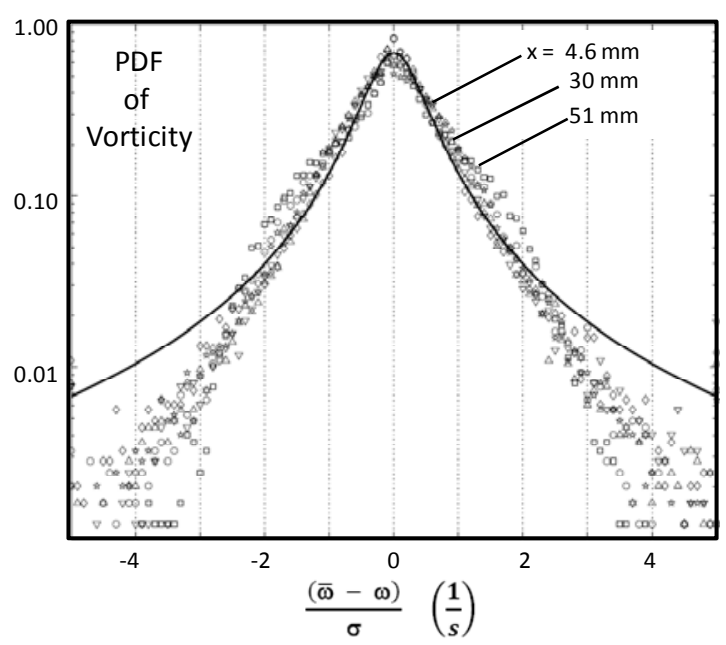

Fig. 15. PDF of Vorticity in the Shear Layer; width of PDF is indicator of the standard deviation of fluctuations of vorticity. 


\section{Conclusions:}

1) Flame and flow properties were measured in an LPP combustor that has a simple cylindrical geometry but contains a real LPP fuel injector that includes several realistic sources of unsteadiness. These sources include flame-flame interactions (by generating both Main and Pilot flames), flameshear layer interactions, and the time-lag due to evaporation of liquid Jet-A fuel. Flame boundaries were recorded using formaldehyde PLIF, while velocities were recorded with PIV. The following were systematically varied: pilot fuel flow rate, main fuel flow rate, inlet air velocity and gas pressure.

2) The premixed nature of the Main flame in an LPP combustor was determined to be one of the primary causes of unsteadiness that caused large r.m.s fluctuations in flow and flame properties. With Pilot only, flame length varied by only $5 \%$, but when Main flame was added the variations increased to $22 \%$. This unsteadiness was found to increase for off-design conditions when a larger fraction of the fuel was burned in the premixed mode.

3) Unsteady parameters were identified that are useful for assessing the ability of LES to simulate the unsteady motions. These parameters were measured; they are the standard deviations in the fluctuations of the:

a) flame surface density (brush thickness);

b) length of the Main flame;

c) length of the Pilot flame,

d) strength of vortices shed in the shear layer.

In addition, profiles of mean velocity, turbulence levels, Reynolds stresses and mean vorticity were recorded.

4) Flame-flame interactions (between the Main and Pilot) were observed. The premixed Main flame cannot be stabilized without the nonpremixed Pilot flame. The degree of unsteadiness increases for off-design conditions when the Pilot fuel flow rate is made insufficiently small. The Main flame is observed to exist well upstream of the location where the Pilot flame overlaps the Main flame. This indicates that it is not the overlap of Pilot flame on the Main fuel stream that determines the base of the Main flame; instead the Main flame appears to be stabilized by hot products from the Pilot flame that are carried upstream by a recirculation zone to the base of the Main flame.

5) The strength of the most intense vortices that are shed in the shear layer was $10,000 \mathrm{~s}^{-1}$, which is more than twice the average vorticity. It was observed that these intense vortices did impinge on the premixed Main flame. It follows that since a RANS simulation can predict only mean vorticity, it must underpredict the strength of the relevant (instantaneous) vorticity that can lead to combustion instabilities, which is a motivation for using LES.

6) Flame-flow interactions are large; heat release caused a drastic reduction in the size and shape of the primary recirculation zone. The recirculation zone changes from an ellipsoidal shape (for two non-reacting cases) to a toroidal shape (for all five reacting cases). With heat release, the axial velocity on the centerline is positive, which is opposite to the non-reacting cases.

7) It was demonstrated that the flame boundaries could be imaged using formaldehyde PLIF for Jet-A fuel at pressures up to $3 \mathrm{~atm}$ in this challenging environment, which has not been done before. Further diagnostic development is needed to extend PLIF imaging to pressures above $3 \mathrm{~atm}$ by removing interferences from the intense luminosity of Jet-A spray flame.

\section{Acknowledgements}

The authors appreciate the technical collaborations that were provided by Prof. Hukam Mongia of Purdue University and by Dr. Shih-Yang Hsieh of GEA. This work was supported by the GE-USA program, and was monitored by Dr. Michael Foust and Dr. Kent Lyle of GEAE. 


\section{References}

1.Dhanuka, S., Temme, J., and Driscoll, J. F., Vortex Shedding and Mixing Layer Effects on Periodic Flashback in a Lean Premixed Prevaporized Gas Turbine Combustor, Proceedings of the Combustion Institute, 32, 2009, pp. 2901-2908.

2.Dhanuka, S., and Driscoll, J. F., Instantaneous Flow Structures in a Gas Turbine Combustor, AIAA Paper 2008-4683.

3.Seyfreid, H., Brackmann, C., Lindholm, A., Linne, M., Barreras, F., Bank, R. Optical Diagnostics Applied to a Gas Turbine Pilot Burner; AIAA J. 45,11, 2702-2709.

4.Meier, U.E., Wolff-Gasmann, D., Stricker, W., LIF Imaging and 2-D Temperature Mapping in a Model Combustor at Elevated Pressure, Aerosp. Sci. Technol. 4 (2000), 404-414.

5.H. C. Mongia,T. J. Held, G. C. Hsiao, and R. P. Pandalai, Challenges and Progress in Controlling Dynamics in Gas Turbine Combustors, J. Propulsion Power, 19, 5, 2003, 822-829.

6. Mongia, H. C., "TAPS - A 4th Generation Propulsion Combustor Technology for Low Emissions," AIAA Paper 2003-2657, 2003.

7. Mongia, H.C., Perspective of Combustion Modeling for Gas Turbine Combustors, AIAA Paper 2004-0156, 2004.

8. Stouffer, S., Ballal, D., Zelina, J., Shouse, D., Hancock, R., and Mongia, H., "Development and Combustion Performance of a High Pressure WSR and TAPS Combustor," AIAA Paper 2005-1416, 2005.

9. Stopper, U, Aigner, M., Meier, W., Sandanandan, R., Stohr, M., Kim, I.S., Flow Field and Combustion Characterization of Premixed Gas Turbine Flames by Planar Laser Techniques, ASME J. of Engineering for Gas Turbines and Power, 131, 021504-1, 2009.

10. Cheng, R.K., Littlejohn, D., Strakey, P.A., Sidwell, T., Laboratory Investigation of a Low Swirl Injector with $\mathrm{H} 2$ and $\mathrm{CH} 4$ at Gas Turbine Conditions, Proc. Combust. Inst. 32, 3001-3009, 2009.

11. Johnson, M., Littlejohn, D., Nazeer, W., Smith, K., and Cheng, R., "A Comparison of the Flowfields and Emissions of High-Swirl
Injectors and Low-Swirl Injectors for Lean Premixed Gas Turbines," Proc. of the Combustion Institute, 30, 2005, 2867-2874.

12. Littlejohn, D., Cheng, R.K., Fuel Effects on a Low Swirl Injector for Lean Premixed Gas Turbines, Proc. Combust. Inst. 31, 3155-3162, 2007.

13. Nogenmyr, K.J., Fureby, C., Bai, X.S., Petersson, P., Collin, R., Linne, M., Large Eddy Simulation and Laser Diagnostic Studies on a Low Swilr Stratified Premixed Flame, Combustion and Flame 156, 25-36, 2009.

14. Roux, S., Lartigue, G., Poinsot, T., Meier, U., Berat, C., Studies of Mean and Unsteady Flow in a Swirled Combustor Using Experiments, Acoustic Analysis, and Large Eddy Simulations, Combust. Flame 141 (2005), 40-54.

15. Ji, J. and Gore, J., "Flow Structure in Lean Premixed Swirling Combustion," Proceedings of the Combustion Institute,Vol. 29, 2002, pp. 861-867.

16. Lee, SY, Seo, S, Broda, JC, Pal, S, Santoro, RJ, An Experimental Estimation of Mean Reaction rate and Flame Structure During Combustion Instability in a Lean Premixed Gas Turbine Combustor, Proc Combust Inst 28, 2000, 775-782.

17. Lieuwen, T. and McManus, K., "Combustion Dynamics in Lean-Premixed Prevaporized (LPP) Gas Turbines," Journal of Propulsion and Power, Vol. 19, 2003, pp. 721721.

18. Ducruix, S, Schuller, T., Durox, Candel, S. Combustion Dynamics and Instabilities, J. Prop. Power 19, 5, 722, 2003.

19. Eggenspieler, G, Menon, S., Large Eddy Simulation of Pollutant Emission in a DOEHAT Combustor, J. Propulsion and Power 20, 6, 1076-1085, 2004.

20. Kim, W.W., Menon, S., Mongia, H.C., Large Eddy Simulation of a Gas Turbine Combustor Flow, Combust. Sci. Technol. 143, 25-62, 1999.

21. Huang, Y., Yang, V., 2004. Bifurcation of flame structure in a lean-premixed swirl stabilized combustor: transition from stable to 
unstable flame. Combustion and Flame 136, 383-389.

22. Huang, Y., Yang, V., Effect of swirl on combustion dynamics in a lean premixed swirl stabilized combustor. Proceedings of the Combustion Institute 30, 2005, 1775-1782.

23. Huang, Y., Sung, H.G., Hsieh, S.-Y., Yang, V., Large Eddy Simulation of Combustion Dynamics of Lean Premixed Swirl Stabilized combustor, J. Propulsion and Power, 19, 5, 2003, 782, 794.

24. Wang, S., Yang, V., Hsiao, G., Hseih, S.Y.., Mongia, H.C., Large Eddy Simulation of Gas Turbine Swirl Injection Flow Dynamics, J. Fluid Mech., 583, 99-122, 2007.

25. Selle, L., Lartigue, G., Poinsot, T., Koch, R., Schildmacher, K., Krebs, W., Prade, B., Kaufmann, P., Veynante, D., Compressible Large Eddy Simulation of Turbulent Combustion in Complex Geometry on Unstructured Meshes, Combustion and Flame 137 (2004) 489-505.

26. Fureby, C., Grinstein, F.F., Li, G., Gutmark, E.J., An Experimental and Computational Study of Multi-Swirl Gas Turbine Combustor, Proc. Combust. Inst. 31, 2007, 3107-3114.

27. Menon, S. and Patel, N., "Subgrid Modeling for Simulation of Spray Combustion in LargeScale Combustors," AIAA Journal, Vol. 44, 2006, pp. 709-723.

28. Patel, N., Menon, S., Simulation of sprayturbulence-flame interactions in a lean direct injection combustor, Combust. Flame 153, 2008, 228-257.

29. Weigand, P., Meier, W., Duan, X. R., Stricker, W., and Aigner, M., "Investigations of Swirl Flames in a Gas Turbine Model Combustor I. Flow Field, Structures, Temperature, and Species Distributions," Combustion and Flame, Vol. 144, No.1-2, 2006, pp. 205-224.

30. Meier, W. , X.R. Duan, P. Weigand, Investigations of swirl flames in a gas turbine model combustor II. Turbulence-chemistry interactions, Combust and Flame 144 (2006) 225-236.

31. Giezendanner-Thoben, R., Meier, U., Meier, W., Aigner, M., Phase Locked Temperature Measurements by Two Line $\mathrm{OH}$ PLIF Thermometry of a Self Excited Combustion
Instability in a Gas Turbine Model Combustor, Flow, Turbulence and Combustion 2005 75:317-333.

32. Janus, B., Dreizler, A., and Janicka, J., "Experimental Study on Stabilization of Lifted Swirl Flames in a Model GT Combustor," Flow, Turbulence and Combust.,75, 2005, pp. 293-315.

33. Feikema, D., Chen, R.H., Driscoll, J.F., Enhancement of Blowout Limits by the Use of Swirl, Combustion and Flame 80, 1990, 183195.

34. Dhanuka, S. and Driscoll, J.F., A Method to Image Flame Fronts in Turbulent Combustion Based on Formaldehyde Fluorescence Gradients, submitted to Experiments in Fluids, 2009.

35. Weber, R. and Dugue, J., "Combustion Accelerated Swirling Flows in High Confinements," Progress in Energy and Combustion Science, Vol. 18, 1992, pp. 349367.

36. Schadow, K. and Gutmark, E., Combustion Instability Related to Vortex Shedding in Dump Combustors and their Active Control, Prog. Energy Comb. Sci. 18, 117, 1992.

37. Li, G., Gutmark, E., 2004. Experimental study of large coherent structures in a swirl dump combustor. AIAA Paper 2004-0133, 2004.

38. Clemens, N., Mungal, M., 1991. A planar Mie scattering technique for visualizing supersonic mixing flows. Experiments in Fluids 11, 175-185.

\section{Appendix A. Methods developed to operate PIV and PLIF under elevated-pressure spray combustion conditions}

For the PIV measurements, the air was seeded with 0.5 micrometer diameter alumina particles which adequately tracked the flow, since the particle relaxation time is $2.85 \mu \mathrm{sec}$ and the relevant flow time scale is $60 \mu$ s. The Stokes number of the particles is 0.005 which is much less than the minimum value of 0.5 that insures that the particles track the flow [38]. The PIV system consists of two Nd:YAG lasers, each providing $60 \mathrm{~mJ} /$ pulse, a LaVision Imager Pro PIV camera, a $60 \mathrm{~mm}$ macro lens (Micro Nikkon) 
operated at $\mathrm{f} / 11$, a programmable timing unit and DaVis data analysis software. The PIV spatial resolution was $2.34 \mathrm{~mm}$, which was the size of the $64 \times 64$ pixel interrogation box. Each velocity image contains 4096 vectors. Mean values typically were the ensemble averages of 200 images.

The flame location was determined from the Planar Laser Induced Fluorescence (PLIF) of formaldehyde $\left(\mathrm{CH}_{2} \mathrm{O}\right)$. Formaldehyde is an important combustion intermediate that is formed on the fuel side of a flame but is quickly destroyed at the flame front due to rapid reaction with $\mathrm{OH}$. Therefore the contour of the maximum gradient of the $\mathrm{CH}_{2} \mathrm{O}$ signal is a good marker of the instantaneous flame front. This was shown to be true in calibration experiments that were conducted in our laboratory for premixed, nonpremixed and partially-premixed cases [34]. Fluorescence was imaged with an Andor ICCD (iStar 734) which was fitted with filters (Schott GG-385 and BG-3) and a mechanical shutter to block the flame luminosity. The camera gate time was $100 \mathrm{~ns}$ and the $1 \mathrm{k} \times 1 \mathrm{k}$ CCD array was binned $2 \times 2$ to yield a spatial resolution of 0.15 mm.
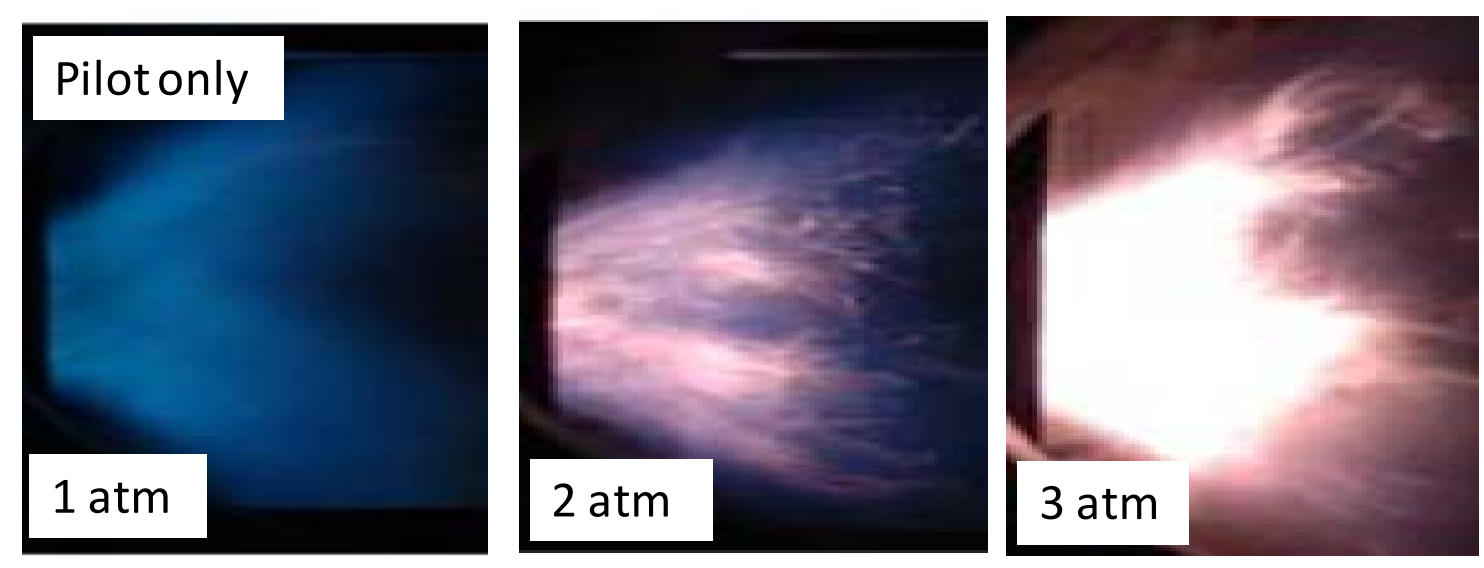

Figure 16. Effect of pressure on the appearance of the Pilot flame (no Main). $506 \mathrm{~K}$ air preheat temperature,

Figure 16 indicates that the luminosity of the Jet-A flame increases significantly as the pressure increases from 1 to $3 \mathrm{~atm}$. At high pressures there are more radiating molecules per unit volume and heavy hydrocarbons such as $\mathrm{PAH}$ and soot precursors are known to be more prevalent. Excessive flame luminosity required that the PIV camera be fitted with an interference filter at $532 \mathrm{~nm}$ having a bandpass of $2 \mathrm{~nm}$, and with a mechanical shutter (Uniblintz VS-25) having a $1 \mathrm{msec}$ exposure time. The LaVision camera electronically gated the first laser pulse, but not the second, requiring the use of a mechanical shutter. Formaldehyde offers advantages that make it the best choice for imaging the flame location in the harsh environment of gas turbine operated with Jet-A fuel at elevated pressures. Fortunately, the $\mathrm{CH}_{2} \mathrm{O}$ PLIF signal is stronger than that from other species because of the relatively large amount of $\mathrm{CH}_{2} \mathrm{O}$ present, and the fact that $\mathrm{CH}_{2} \mathrm{O}$ can be excited by the strong $355 \mathrm{~nm}$ line of a $\mathrm{Nd}$ :YAG laser. Laser energy was $150 \mathrm{~mJ} /$ pulse. Fluorescence from soot and PAH can cause an interference, but this was minimized by using large laser energies. As laser energy increases, the fluorescence from soot and PAH saturates (and remains constant) but fluorescence from $\mathrm{CH}_{2} \mathrm{O}$ continues to increase. 